\title{
Feasibility Study to determine if administration of Carbonic anhydrase inhibitor Acetazolamide (Diamox) will cause aquaresis but prevent hyponatriemia in a healthy population: SALT Study
}

\author{
Gurinder S Grewal $^{1}$, Teri M Kozik ${ }^{1 *}$, Mary C Hickman ${ }^{1}$, Therese F Connolly ${ }^{1}$, Randeep S Bajwa ${ }^{1}$ and Mouchumi Bhattacharyya ${ }^{2}$ \\ ${ }^{1}$ St. Joseph's Medical Center, Research Department, 1800 N. California Street, Stockton CA 95204, USA \\ ${ }^{2}$ University of the Pacific, Mathematics Department, Stockton CA 95204, USA
}

\begin{abstract}
Introduction: Hyponatremia is a common electrolyte disorder observed in heart failure (HF) patients making it difficult to treat with diruetics. Additionally, HF remains one of the costliest diagnoses in the United States with an estimated cost of around $\$ 31$ billion for Medicare recipients. Finding an effective and inexpensive treatment becomes imperative to offset these staggering rates.

Objective: The objective of this pilot study was to determine the safety of using acetazolamide in healthy individuals and to confirm that its properties would be that of an aquaretic rather than a diuretic.

Methods: Baseline serum samples for electrolyte levels and kidney function were obtained. Subjects were then administered $250 \mathrm{mg}$ of acetazolamide orally every day for 5 days. On the final day of medication administration, each subject once again repeated the same laboratory tests.

Results: Twelve healthy subjects participated. No significant change in urine sodium, urine osmolality, and serum sodium was observed at the completion of the study period.

Conclusions: Acetazolamide has been classified as a diuretic, but our study indicates that it may actually act more like an aquaretic. We showed a mild trended increase yet no significant change in serum sodium levels in healthy individuals after five days. Hence, future studies in hypervolemic hyponatremic HF patients may elucidate this medications ability to improve the sodium levels, fluid status and mortality rates cost effectively in this population.
\end{abstract}

\section{Introduction}

Hyponatremia is a common electrolyte disorder observed in hospitalized patients especially those with heart failure (HF), making it difficult to treat with diuretics [1,2]. It occurs in more than $20 \%$ of $\mathrm{HF}$ patients, especially in those with advanced disease [3]. Data from three large HF registries [4-6] has shown that hyponatremia in this population during hospitalization is an independent predictor for complications with long term outcomes and mortality, increased length of stay, and increased cost. With improvements in serum sodium levels, 60-day mortality rates have shown to decrease significantly [7]. The standard of care for treatment in euvolemic or hypervolemic hyponatremic states is fluid restriction and if possible, stopping the offending medication (most often a potent diuretic) [8]. Continuing diuretics in the presence of severe hyponatremia is a difficult problem. The carbonic anhydrase inhibitor known as acetazolamide, has been used in medicine for many decades to treat conditions which inhibits bicarbonate reabsorption while increasing sodium absorption in the kidney [9]. This antivasopressin effect and loss of free water is known as aquaresis. One common use for acetazolamide is for glaucoma patients to decrease aqueous humor production and therefore intraocular pressure [10]. In glaucoma patients prescribed acetazolamide, anecdotal observations of increased serum sodium levels have been noted.

\section{Aim}

The aims of this pilot study were to determine the safety of using acetazolamide in healthy individuals to confirm that its properties would be that of an aquaretic and not a diuretic medication.

\section{Methods}

This was an observation study of healthy individuals between the ages of 18-50 years old. Institutional Review Board approval was obtained prior to all research activities.

Subjects were excluded that had an allergy to sulfa medications, hypertension, thyroid disorders, diabetes, kidney disease, heart disease, neurological disease, lung disease, and auto-immune disease. Additional exclusions were pregnancy, use of neutraceuticals or any prescription medications that could alter electrolytes.

${ }^{\star}$ Correspondence to: Teri M Kozik, St. Joseph's Medical Center, Research Department, 1800 N. California Street, Stockton CA 95204, USA, E-mail: Teri. Kozik@DignityHealth.org

Key words: acetazolamide, heart failure, hyponatremia, hypervolemia

Received: July 05, 2018; Accepted: July 25, 2018; Published: August 02, 2018 
Grewal GS (2018) Feasibility Study to determine if administration of Carbonic anhydrase inhibitor Acetazolamide (Diamox) will cause aquaresis but prevent hyponatriemia in a healthy population: SALT Study

Once consent was obtained, baseline serum samples for electrolyte levels and kidney function were obtained on day one. Once these were determined to be normal, subjects were administered $250 \mathrm{mg}$ of acetazolamide orally every day for 5 days. On the final day of medication administration, each subject once again repeated the same laboratory tests [11].

\section{Statistical analysis and results}

Twelve subjects [11] participated in the study; average age was 36, \pm 7 years, 9 were men. Because of the small sample size, normality tests were conducted of which only three of the seven variables passed, therefore traditional paired $t$-test was used for those three and the nonparametric Wilcoxon test (paired) was used for the remaining four variables.

No significant change was observed from baseline to completion of study for urine sodium, urine osmolality, and serum sodium. There was a significant change, however clinically insignificant, in serum blood urea nitrogen (BUN), serum creatinine, serum potassium, and serum chloride (Table 1).

\section{Adverse events/safety}

No major adverse events were seen in any of the 12 subjects. Minor events occurred in three subjects. Two subjects complained of tingling to their hands and feet. One of these two withdrew consent on the third day because of these symptoms and the second subject withdrew on day four also because of the symptoms. Both had normal labs studies at the last day of participation. A third subject had a drop in their potassium level to 3.3 ( 0.2 below the normal limit) on the final day and was administered potassium replacement.

\section{Discussion}

Acetazolamide has been used clinically in glaucoma, to treat and prevent high altitude pulmonary edema, and to correct metabolic alkalosis in critically ill intensive care patients. This medication has been classified as a diuretic, but our study indicates that it may actually act more like an aquaretic by causing mild hypernatremia and mild metabolic acidosis. These two properties are useful in correcting patients with metabolic alkalosis or those who have an inappropriate level of the hormone vasopressin which is also known as antidiuretic hormone $(\mathrm{ADH})$ by correcting hyponatremia. Vasopressin, or $\mathrm{ADH}$ acts in the renal collecting ducts to increase water permeability leading to decreased urine formation, increased blood volume, and a decrease in serum sodium [12].

Patients with HF and hyponatremia have a poor prognosis [4-6] and other than fluid restriction, are hard to treat. Neurohormones

Table 1. Results

\begin{tabular}{|l|c|c|c|c|c|}
\hline & BL mean & $\begin{array}{c}\text { Final } \\
\text { mean }\end{array}$ & CI & ES & $p$ \\
\hline Urine sodium $(\mathrm{mmol} / \mathrm{L})$ & 138 & 133 & $-55,53$ & .06 & .48 \\
\hline Urine osmolality $(\mathrm{mOsmol} / \mathrm{kg})$ & 702 & 597 & $-90,254$ & .31 & .23 \\
\hline $\begin{array}{l}\text { Serum blood urea nitrogen } \\
(\mathrm{mg} / \mathrm{dL})\end{array}$ & 13.3 & 16.7 & $-7,-1$ & -.81 & .02 \\
\hline Serum creatinine $(\mathrm{mg} / \mathrm{dL})$ & .9 & 1.0 & $-.20,-.10$ & -2.15 & .00 \\
\hline Serum sodium $(\mathrm{mmol} / \mathrm{L})$ & 142 & 143 & $-3,1$ & -.35 & .28 \\
\hline Serum potassium $(\mathrm{mmol} / \mathrm{L})$ & 4.1 & 3.9 & $.05, .50$ & .94 & .01 \\
\hline Serum chloride $(\mathrm{mmol} / \mathrm{L})$ & 104 & 110 & $-7.04,-3.68$ & -2.15 & .00 \\
\hline Serum $\mathrm{CO}_{2}(\mathrm{mmol} / \mathrm{L})$ & 27.0 & 23.2 & $2.50,5.00$ & 2.22 & .00 \\
\hline
\end{tabular}

$\mathrm{BL}=$ baseline $\mathrm{CI}=$ confidence intervals $; \mathrm{ES}=$ effect size; $\mathrm{mmol} / \mathrm{L}=$ millimoles per liter; $\mathrm{mOsmol} / \mathrm{kg}=$ milliosmoles per kilogram; $\mathrm{mg} / \mathrm{dL}=$ milligrams per deciliter such as renin, vasopressin, and norepinephrine are secreted in response to low cardiac output and blood pressure in this population [6] as an attempt to return perfusion pressure to normal. Unfortunately, this can lead to hypervolemic hyponatremia and its subsequent sequela.

Heart failure remains one of the leading healthcare burdens in the United States with an estimated cost of $\$ 31$ billion for Medicare recipients. It is estimated that this will increase to $\$ 53$ billion by 2030 most of which is due to hospitalizations [11]. Mortality rates in hyponatremic hospitalized patients at 60 days post discharge can be reduced from over $21 \%$ to approximately $11 \%$ with serum sodium correction [7]. Because loop diuretics can decrease sodium levels significantly, patients with hyponatremia in a fluid excess state, may benefit from the use of acetazolamide. Acetazolamide costs around $\$ 0.50$ per tablet which may be an inexpensive yet effective way to treat this population.

\section{Limitations}

This was a small sample observational feasibility study conducted on healthy individuals. The objective was to determine the safety of using acetazolamide to cause aquaresis in individuals without affecting the sodium level so that a larger heart failure study could be considered in the future.

\section{Conclusions}

In our current crises of healthcare costs and burden to our Medicare system, a larger study of heart failure patients with hyponatremia should be considered. Examining this older medication may help determine similar efficacy and safety of it use in this population of heart failure patients.

We have observed in our clinical practice anecdotally that in severely decompensated HF patients with hyponatremia, not only did acetazolamide correct the sodium level, but also allowed us to continue loop diuretics to stabilize their fluid status. Our findings in this small sample confirmed our antecdotal observations that acetazolamide can lead to an increase in sodium levels because of free water loss (aquaresis).

We showed the safety of acetazolamide in a healthy population which was well tolerated. Therefore, a future, larger controlled study is planned to help elucidate our hypothesis that hypervolemic hyponatremic HF patients can be treated safely using acetazolamide to improve their fluid status and sodium levels.

\section{Funding}

This research did not receive grant or extramural funding from any public, commercial, or not-for-profit sectors.

All authors declare no conflict of interest.

\section{References}

1. Grodin JL (2016) Pharmacologic Approaches to Electrolyte Abnormalities in Heart Failure. Curr Heart Fail Rep 13: 181-189. [Crossref]

2. Verbalis JG, Goldsmith SR, Greenberg A, Schrier RW, Sterns RH (2007) Hyponatremia treatment guidelines 2007: expert panel recommendations. Am J Med 120: S1-S21. [Crossref]

3. Upadhyay A, Jaber BL, Madias NE (2006) Incidence and prevalence of hyponatremia Am J Med 119: S30-S35. [Crossref]

4. Arévalo Lorido JC, Carretero Gómez J, Formiga F, Montero Pérez-Barquero M, Trullás Vila JC, et al. (2013) Hyponatremia as predictor of worse outcome in real world patients admitted with acute heart failure. Cardiol J 20: 506-512. [Crossref] 
Grewal GS (2018) Feasibility Study to determine if administration of Carbonic anhydrase inhibitor Acetazolamide (Diamox) will cause aquaresis but prevent hyponatriemia in a healthy population: SALT Study

5. Lu DY, Cheng HM, Cheng YL, Hsu PF, Huang WM, et al. (2016) Hyponatremia and Worsening Sodium Levels Are Associated with Long-Term Outcome in Patients Hospitalized for Acute Heart Failure. J Am Heart Assoc 5: e002668. [Crossref]

6. Dunlap ME, Hauptman PJ, Amin AN, Chase SL, Chiodo JA $3^{\text {rd }}$, et al. (2017) Current Management of Hyponatremia in Acute Heart Failure: A Report From the Hyponatremia Registry for Patients With Euvolemic and Hypervolemic Hyponatremia (HN Registry). J Am Heart Assoc 6. [Crossref]

7. Rossi J, Bayram M, Udelson JE, Lloyd-Jones D, Adams KF, et al. (2007) Improvement in hyponatremia during hospitalization for worsening heart failure is associated with improved outcomes: insights from the Acute and Chronic Therapeutic Impact of a Vasopressin Antagonist in Chronic Heart Failure (ACTIV in CHF) trial. Acute Card Care 9: 82-86. [Crossref]
8. Schrier RW, Bansal S (2008) Diagnosis and management of hyponatremia in acute illness. Curr Opin Crit Care 14: 627-634. [Crossref]

9. Kassamali R, Sica DA (2011) Acetazolamide: a forgotten diuretic agent. Cardiol Rev 19: 276-278. [Crossref]

10. Kaur IP, Smitha R, Aggarwal D, Kapil M (2002) Acetazolamide: future perspective in topical glaucoma therapeutics. Int J Pharm 248: 1-14. [Crossref]

11. Page RL 2nd, O’Bryant CL, Cheng D, Dow TJ, Ky B, et al. (2016) Drugs That May Cause or Exacerbate Heart Failure: A Scientific Statement from the American Heart Association. Circulation 134: e32-e69. [Crossref]

12. Mohrman DE, Heller LJ (2014) Cardiovascular Physiology. In: Education M-H, ed.

Copyright: $\odot 2018$ Grewal GS. This is an open-access article distributed under the terms of the Creative Commons Attribution License, which permits unrestricted use, distribution, and reproduction in any medium, provided the original author and source are credited. 